\title{
Sensitivity of Mycosphaerella pinodes to Pyraclostrobin Fungicide
}

Robyne Bowness, Food and Bio-Industrial Crops Branch, Alberta Agriculture and Rural Development, Lacombe, AB, T4L 1W1, Canada; Bruce D. Gossen, Agriculture and Agri-Food Canada Research Centre, Saskatoon, SK, S7N 0X2, Canada; Kan-Fa Chang, Crop Diversification Centre North, Alberta Agriculture and Rural Development, Edmonton, AB, T5Y 6H3, Canada; Rubella Goswani, Dupont Crop Protection, Stine Haskell Research Center, Newark, DE 19711; Christian J. Willenborg, Department of Plant Sciences, University of Saskatchewan, Saskatoon, SK, S7N5A8, Canada; Michael Holtz, Field Crop Development Centre, Alberta Agriculture and Rural Development, Lacombe; and Stephen E. Strelkov, Department of Agricultural, Food and Nutritional Science, University of Alberta, Edmonton, AB, T6G 2P5, Canada

\begin{abstract}
Bowness, R., Gossen, B. D., Chang, K.-F., Goswani, R., Willenborg, C. J., Holtz, M., and Strelkov, S. E. 2016. Sensitivity of Mycosphaerella pinodes to pyraclostrobin fungicide. Plant Dis. 100:192-199.

Mycosphaerella blight, caused by Mycosphaerella pinodes, is a destructive disease of field pea that is managed using foliar fungicides. Strobilurin fungicides have been used in western Canada for disease management since 2003. To assess the baseline sensitivities of M. pinodes isolates to the strobilurin fungicide pyraclostrobin, the effective concentration to reduce mycelial growth by $50 \%\left(\mathrm{EC}_{50}\right)$ was determined for 70 isolates collected prior to 2003 from Alberta, Saskatchewan, North Dakota, and Washington State. Each of these isolates was sensitive to pyraclostrobin, with $\mathrm{EC}_{50}$ values ranging from 0.03 to $0.29 \mathrm{mg} \mathrm{liter}^{-1}$. The pyraclostrobin concentrations required to reduce conidia

germination by $50 \%$ was lower, ranging from 0.008 to $0.041 \mathrm{mg} \mathrm{liter}^{-1}$. In all, 324 isolates collected in 2010 and 2011 were tested for high levels of insensitivity by examining mycelial growth using a discriminatory dose of $5 \mathrm{mg} \mathrm{liter}^{-1}$. Nineteen isolates were highly insensitive to pyraclostrobin, with $\mathrm{EC}_{50}$ values of 80 to $216 \mathrm{mg} \mathrm{liter}^{-1}$. Conidia of these isolates germinated when exposed to a discriminatory dose of $0.1 \mathrm{mg} \mathrm{liter}^{-1}$. Insensitive isolates infected field pea plants treated with pyraclostrobin but sensitive isolates did not. The identification of insensitive isolates indicates that insensitivity may be emerging in the pathogen population.
\end{abstract}

Mycosphaerella blight, caused by Mycosphaerella pinodes, is a destructive foliar disease of field pea in western Canada and around the world (Banniza and Vandenberg 2003; Beasse et al. 1999; Bretag et al. 2006; Davidson and Ramsey 2000). Yield losses vary considerably but, in Canada, losses were reported to be as high as $50 \%$ (Conner et al. 2007). M. pinodes is part of the Ascochyta blight complex, which comprises three fungal pathogens: Ascochyta pisi Lib., (Chilvers et al. 2009), Mycosphaerella pinodes (Berk. \& A. Bloxam) Vestergr. (anamorph A. pinodes L. K. Jones), and Phoma pinodella (L. K. Jones) Morgan-Jones \& K. B. Burch. Of the three, $M$. pinodes is by far the most abundant in Canada, causing $90 \%$ of reported Ascochyta blight infections (Ali et al. 1982).

M. pinodes is best managed by reducing the amount of available inoculum and suppressing the subsequent epidemic. The most commonly utilized strategy for management of Mycosphaerella blight is the application of fungicide sprays in a preventative and systematic schedule (Beasse et al. 2000). Multiple sprays, initiated at early to midflowering, provide effective disease control and improve yield (Warkentin et al. 2000). The use of fungicides for disease management on field crops has increased rapidly in recent years (Gossen et al. 2014). However, the selection pressure imposed by repeated use of fungicides is the leading contributor to fungicide insensitivity in pathogen populations (Gisi et al. 1997). This risk must be taken into consideration when applying a single fungicide repeatedly, or those with the same mode of action (Brent and Holloman 2007b).

The strobilurin group of fungicides have been widely used since 1996. They are single-site mode-of-action fungicides classified as

Corresponding author: R. Bowness; E-mail: robyne.bowness@gov.ab.ca

*The $\boldsymbol{e}$-Xtra logo stands for "electronic extra" and indicates that three supplementary figures and two supplementary tables are published online.

Accepted for publication 12 July 2015.

http://dx.doi.org/10.1094/PDIS-03-15-0350-RE

(C) 2016 The American Phytopathological Society quinine outside inhibitors (Qol), because they bind the Qo site of cytochrome $\mathrm{b}$, inhibiting mitochondrial respiration (Bartlett et al. 2002). This causes an energy deficiency due to lack of single ATP (Bartlett et al. 2002). The Fungicide Resistance Action Committee (FRAC 2015) has identified strobilurins as a high risk for insensitivity due to their site-specific mode of action, especially with repeated use.

Pyraclostrobin is a strobilurin fungicide that has been widely used in Canada since 2002, and is the active ingredient in the fungicide Headline 250 EC (BASF Canada, Mississauga, ON, Canada). It provides broad-spectrum control of many plant pathogens, including the Ascochyta and Mycosphaerella spp. on pulse crops (BASF 2011). In Canada, the research into pyraclostrobin insensitivity in field crop pathogens has focused on A. rabiei on chickpea, which has developed qualitative insensitivity to this product (Chang et al. 2007; Gossen and Anderson 2004; Thaher 2011; Wise et al. 2008, 2009). Similarities in the risk characteristics between A. rabiei on chickpea and $M$. pinodes on field pea indicate that there is a possibility of fungicide insensitivity developing in M. pinodes. Also, three species in the Mycosphaerella genus are known to be insensitive to strobilurins: M. fijiensis, M. citri, and M. graminicola (Gisi et al. 1997; Grasso et al. 2006; Keinath 2009; Miguez et al. 2003; Mondal et al. 2005).

There are two types of fungicide insensitivity: quantitative and qualitative. Quantitative insensitivity results in the pathogen becoming less sensitive to the fungicide, although higher rates or more fungicide applications are still effective. Qualitative insensitivity causes the pathogen to become completely insensitive to the active ingredient and control is no longer possible at field rates. Insensitivity to the strobilurin fungicides is generally qualitative (Ypema and Gold 1999).

In vitro research on fungal respiration in the presence of respiration-inhibiting fungicides such as the strobilurins has shown that certain microorganisms can use an alternative respiration pathway, involving the production of a cyanide-insensitive alternative oxidase (AOX) (Miguez et al. 2003). This enables the bc complex in the mitochondrial respiration chain to be bypassed and allows mycelial growth and spore germination even in the presence of 
the fungicide (Olaya and Koller 1999; Vincelli and Dixon 2002; Ziogas et al. 1997). Although alternative respiration has not been directly identified in QoI-insensitive pathogens (Avila-Adame et al. 2003), the induction of this alternative pathway of respiration can serve as an effective rescue mechanism when pathogen sensitivities are tested in the absence of a host. Salicylhydroxamic acid (SHAM) is used to inhibit AOX. This chemical is routinely included in QoI in vitro fungicide sensitivity assessments, because alternative respiration may affect the results of these assays, leading to incorrect assessments of fungicide sensitivity (Miguez et al. 2003; Wise et al. 2009).

Establishing the baseline sensitivity of the pathogen prior to exposure of the population to the active ingredient in the fungicide is very useful for subsequent monitoring to detect the development of fungicide insensitivity (Avenot and Michailides 2007; Brent and Holloman 2007a). Studies on strobilurin insensitivity in M. pinodes have not been conducted. Considering the widespread use of the site-specific mode of action of pyraclostrobin fungicide and the identification of strobilurin insensitivity in closely related species, it was suspected that similar insensitivity issues may have already developed.

The objectives of this study were to (i) quantify the baseline sensitivity of $M$. pinodes isolates from the Canadian prairies and northern Great Plains of the United States to pyraclostrobin fungicide using radial growth assessments, (ii) determine whether either inhibiting AOX with SHAM or using the formulated product (Headline) instead of the technical-grade product affected the baseline sensitivity assessments, (iii) determine whether baseline assessments using conidial germination produced the same pattern of response as radial growth assessments, and (iv) compare the reaction of $M$. pinodes isolates collected in 2010 and 2011 with that of baseline isolates to determine whether sensitivity to pyraclostrobin is changing in western Canada and the Northern Great Plains of the United States.

\section{Materials and Methods}

Baseline sensitivity. Preparation of isolates. In all, 40 M. pinodes isolates were obtained from the Saskatoon Research Centre, Agriculture and Agri-Food Canada, Saskatoon, SK, Canada and 30 isolates were obtained from the $M$. pinodes collection at the United States Department of Agriculture in Pullman, WA. These cultures were collected prior to 2003, before the registration of QoI fungicides in those geographical areas, and, therefore, represent a true baseline collection of isolates that have not been exposed to QoI fungicides. These isolates were confirmed to be $M$. pinodes based on colony and spore morphology. They were mass transferred onto water agar (WA; Difco Laboratories), allowed to grow for 5 days, and purified by isolation from hyphal tips. The cultures were then transferred onto commercial potato dextrose agar (PDA; Difco Laboratories) and incubated at $20 \pm 2^{\circ} \mathrm{C}$ for 14 days under white fluorescent light with a 16-h photoperiod, and their identity was again confirmed by colony and spore morphology, as before.

Radial growth assessments. Seventy baseline isolates of $M$. pinodes were inoculated onto PDA and incubated for 1 week. Then, 5-mm-diameter agar plugs taken from the edge of each actively growing culture were transferred, mycelium side down, onto the center of a fresh petri dish of PDA measuring 15 by $100 \mathrm{~mm}$. To determine whether formulation affected the sensitivity of $M$. pinodes to pyraclostrobin, the response to a formulated commercial product (Headline) was compared with the technical-grade product $(89 \%$ active ingredient [a.i.]; BASF) in a radial growth study. Technicalgrade pyraclostrobin was prepared by dissolving the powdered product into acetone. The solution was filter sterilized before adding to the cooled, autoclaved medium. The final concentration of acetone in the medium was $0.01 \%$ by volume. For the formulated product, Headline fungicide was serially diluted using sterilized deionized water. The Headline solutions were added to autoclaved PDA after it had cooled to $55^{\circ} \mathrm{C}$. The treatments were concentrations of fungicide in amended PDA of pyraclostrobin at 0 (control), 0.001, 0.01, 0.05, 0.1, 0.5, 1, 5, 10 , or $50 \mathrm{mg} \mathrm{liter}^{-1}$. After inoculation, the dishes were incubated for 7 days. The colony diameter (radial growth) was determined by measuring each culture at its widest point and then at a right angle to the first measurement. The two measurements were averaged and the 5-mm core subtracted. The colonies were incubated for another 7 days and measured again. The measurements taken 14 days after inoculation are presented because they showed more pronounced and consistent differences among the isolates than the assessments at 7 days. The experiment was arranged in a completely randomized design with one dish per replicate and four replicates per treatment. The experiment was repeated once. This design was used in all subsequent in vitro studies.

To assess the effect of SHAM (Sigma-Aldrich) on the response of $M$. pinodes to pyraclostrobin, a radial growth study was conducted using formulated product media amended with and without SHAM. SHAM was prepared by dissolving $100 \mathrm{mg}$ of SHAM into $1 \mathrm{ml}$ of methanol and adding the mixture to the PDA medium at a concentration of $0.01 \%$ by volume $\left(100 \mu \mathrm{g} \mathrm{ml}^{-1}\right)$, as described by Wise et al. (2008). SHAM was filter sterilized and added to the autoclaved medium after cooling to $55^{\circ} \mathrm{C}$. The study was conducted using the methods and pyraclostrobin treatment concentrations described previously.

Conidial germination assessments. Of the 70 baseline isolates, 50 were inoculated onto PDA and incubated as described previously. After 7 days, conidia were collected from each culture by adding $2 \mathrm{ml}$ of sterilized deionized water containing $0.05 \%$ ( $\mathrm{vol} / \mathrm{vol}$ ) Tween 20 to each petri dish and then gently dislodging the conidia with a glass rod or a transfer loop. The resulting conidial suspension was collected and adjusted with a hemocytometer to $2 \times 10^{5}$ spores $\mathrm{ml}^{-1}$, and $100 \mu \mathrm{l}$ of suspension was pipetted onto each of four replicate dishes of Headline-amended PDA plus SHAM at $100 \mu \mathrm{g} \mathrm{ml}^{-1}$. Based on the results of the radial growth trials, only formulated product was used. The treatments consisted of pyraclostrobin at 0 (control), $0.001,0.005,0.01,0.05,0.1,0.5,1,5$, or $10 \mathrm{mg} \mathrm{liter}^{-1}$. Following $24 \mathrm{~h}$ of incubation at $20 \pm 2^{\circ} \mathrm{C}$, the germination of 100 conidia per replicate petri dish was assessed under a compound microscope with a $\times 200$ objective lens. A conidium was considered germinated if the germ tube was at least as long as the conidium itself (Pasche et al. 2004).

Sensitivity of M. pinodes isolates collected in 2010 and 2011. Preparation of isolates. In total, 324 isolates of $M$. pinodes were obtained from infected plant samples collected from commercial fields in Alberta, Saskatchewan, North Dakota, and Washington State in 2010 and 2011. These isolates represented populations that may have been exposed to pyraclostrobin fungicides for up to 8 years. Sections of the leaf containing disease lesions were removed and surface sterilized in $5 \% \mathrm{NaOCl}$ for $25 \mathrm{~s}$, rinsed three times with deionized water, and allowed to dry for $15 \mathrm{~min}$ in a laminar flow hood. The leaf sections were transferred onto PDA and incubated for 7 days at $20 \pm 2^{\circ} \mathrm{C}$. Putative cultures of $M$. pinodes were then transferred onto WA plates, incubated for 5 days, and purified by transferring hyphal tips onto PDA. The pure cultures were incubated for 14 days, their identity was confirmed based on culture and spore morphology, and they were transferred onto PDA slants and stored at $4^{\circ} \mathrm{C}$.

Testing for sensitivity. Each of the 324 isolates collected in 2010 and 2011 was tested using the radial growth procedure described previously at a discriminatory dose of $5.0 \mathrm{mg} \mathrm{liter}^{-1}$ using formulated product (Headline) and $0.1 \%$ SHAM. This concentration was selected to identify highly insensitive isolates based on the response of the baseline isolates, where $5.0 \mathrm{mg} \mathrm{liter}^{-1}$ consistently reduced colony growth by more than $70 \%$ but some growth still occurred. Isolates were categorized as sensitive if growth was reduced by more than $70 \%$, intermediate if growth was reduced between 30 and $70 \%$, and insensitive if growth was reduced by less than $30 \%$ by Headline (adapted from Thaher 2011). The response of the exposed isolates (from 2010 and 2011) was compared with the response of the baseline isolates to see if the sensitivity level of the populations had changed.

Each isolate that was designated as insensitive in the radial growth study was also tested for insensitivity at a discriminatory dose of $0.1 \mathrm{mg}$ liter $^{-1}$ using the conidial germination procedure described 
Table 1. Analysis of variance for radial growth of the baseline isolates of Mycosphaerella pinodes from Saskatchewan and Washington to assess their response to formulated product versus technical-grade formulation of pyraclostrobin fungicide

\begin{tabular}{|c|c|c|c|c|c|}
\hline Isolate & $\operatorname{Pr}>F$ & $F$ value & $R^{2}$ & Coefficient of variation & $\log _{10}$ mean growth ${ }^{a}$ \\
\hline \multicolumn{6}{|c|}{ Saskatchewan } \\
\hline Sep0002 & 0.280 & 1.28 & 0.95 & 9.70 & 1.47 \\
\hline Sep0004 & 0.715 & 0.14 & 0.95 & 9.86 & 1.46 \\
\hline Sep0008 & 0.085 & 3.52 & 0.91 & 20.61 & 1.34 \\
\hline Mar0405 & 0.283 & 1.25 & 0.72 & 25.65 & 1.40 \\
\hline Mar0412 & 0.162 & 2.22 & 0.97 & 11.92 & 1.33 \\
\hline Mar0413 & 0.659 & 0.21 & 0.95 & 12.74 & 1.44 \\
\hline Mar0419 & 0.423 & 0.69 & 0.92 & 19.71 & 1.35 \\
\hline Mar0425 & 0.372 & 0.87 & 0.95 & 14.24 & 1.39 \\
\hline Mar0426 & 0.180 & 2.02 & 0.96 & 9.72 & 1.42 \\
\hline Mar0427 & 0.297 & 1.19 & 0.95 & 14.91 & 1.31 \\
\hline Mar0435 & 0.035 & 5.68 & 0.97 & 10.43 & 1.34 \\
\hline Mar0448 & 0.562 & 0.36 & 0.96 & 8.25 & 1.49 \\
\hline Mar0452 & 0.791 & 0.07 & 0.95 & 10.55 & 1.50 \\
\hline Mar0458 & 0.476 & 0.54 & 0.95 & 11.67 & 1.47 \\
\hline Mar0463 & 0.973 & 0.00 & 0.95 & 8.85 & 1.48 \\
\hline Mar0464 & 0.274 & 1.29 & 0.65 & 46.31 & 1.26 \\
\hline Apr0404 & 0.126 & 2.70 & 0.94 & 11.98 & 1.45 \\
\hline Apr0405 & 0.373 & 0.86 & 0.94 & 12.45 & 1.47 \\
\hline Apr0409 & 0.994 & 0.00 & 0.95 & 11.98 & 1.41 \\
\hline Aug0002 & 0.056 & 4.55 & 0.97 & 11.85 & 1.25 \\
\hline Aug0004 & 0.964 & 0.00 & 0.80 & 53.14 & 1.12 \\
\hline Aug0006 & 0.043 & 5.11 & 0.94 & 22.64 & 1.18 \\
\hline Nov0456 & 0.373 & 0.86 & 0.89 & 17.43 & 1.48 \\
\hline \multicolumn{6}{|l|}{ Washington } \\
\hline MP01 & 0.146 & 2.42 & 0.93 & 19.21 & 1.34 \\
\hline MP03 & 0.340 & 0.99 & 0.95 & 20.50 & 1.25 \\
\hline MP04 & 0.641 & 0.23 & 0.96 & 11.30 & 1.42 \\
\hline MP05 & 0.022 & 7.09 & 0.98 & 7.82 & 1.44 \\
\hline MP06 & 0.265 & 1.37 & 0.95 & 13.38 & 1.37 \\
\hline MP07 & 0.246 & 1.50 & 0.95 & 11.19 & 1.48 \\
\hline MP10 & 0.250 & 1.47 & 0.92 & 19.82 & 1.39 \\
\hline MP11 & 0.555 & 0.37 & 0.89 & 24.50 & 1.32 \\
\hline MP12 & 0.343 & 0.98 & 0.92 & 18.63 & 1.39 \\
\hline MP14 & 0.870 & 0.03 & 0.94 & 17.99 & 1.33 \\
\hline MP15 & 0.084 & 3.56 & 0.96 & 11.83 & 1.35 \\
\hline MP17 & 0.225 & 1.65 & 0.92 & 13.41 & 1.52 \\
\hline MP18 & 0.203 & 1.83 & 0.95 & 12.43 & 1.44 \\
\hline MP22 & 0.966 & 0.00 & 0.93 & 18.47 & 1.33 \\
\hline MP24 & 0.656 & 0.21 & 0.85 & 35.71 & 1.33 \\
\hline MP26A & 0.089 & 3.48 & 0.94 & 21.37 & 1.26 \\
\hline MP26B & 0.115 & 2.89 & 0.96 & 10.40 & 1.40 \\
\hline MP27 & 0.779 & 0.08 & 0.95 & 20.10 & 1.24 \\
\hline MP28 & 0.816 & 0.06 & 0.93 & 14.76 & 1.36 \\
\hline MP30 & 0.035 & 5.68 & 0.95 & 13.83 & 1.40 \\
\hline AP10 & 0.093 & 3.34 & 0.97 & 11.01 & 1.35 \\
\hline
\end{tabular}

a Dependent variable was $\log _{10}$ transformation of percent growth response with 1 degree of freedom and $P \leq 0.05$.

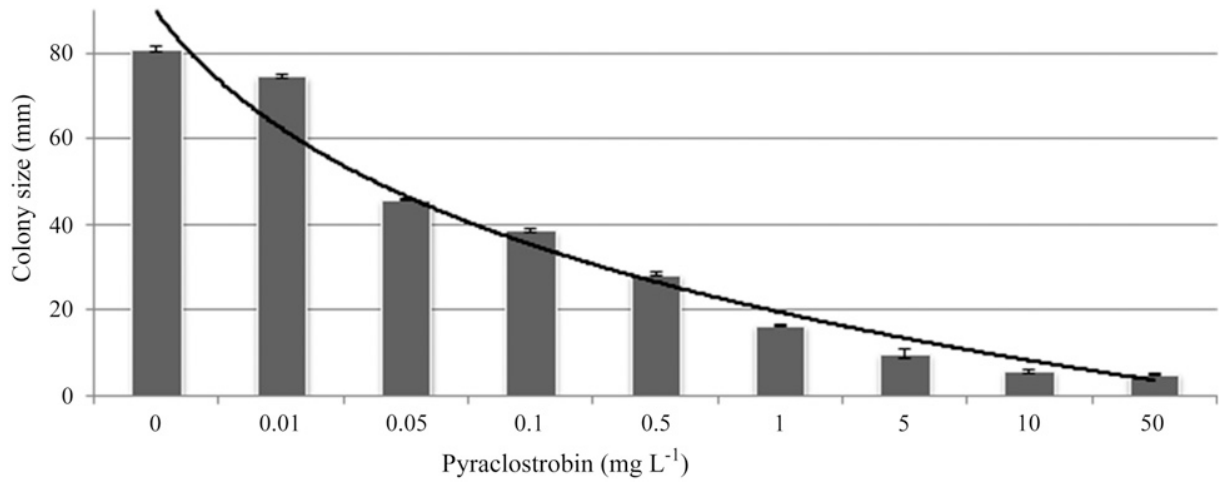

Fig. 1. Radial growth of a representative sensitive isolate of Mycosphaerella pinodes (R0101R) in response to media amended with a range of concentrations of pyraclostrobin (formulated product, no salicylhydroxamic acid). 
previously. An additional 25 isolates designated as sensitive in the radial growth study were also assessed. The lower discriminatory dose was chosen based on the previous conidial germination study, which indicated that a lower dose is required to inhibit conidial germination than is necessary to inhibit radial growth, and was selected to identify highly insensitive isolates. The isolates were classified as sensitive, intermediate, or insensitive, as described previously. The trial was repeated once.

Effective concentration to reduce mycelial growth of insensitive isolates. To assess the degree of insensitivity of the insensitive isolates, a radial growth study was conducted using Headline-amended PDA and $0.01 \%$ SHAM, as described previously. The treatments consisted of pyraclostrobin at $0,5,10,20,40,80,160$, or $320 \mathrm{mg} \mathrm{liter}^{-1}$. Colony growth was measured after 14 days and effective concentration to reduce mycelial growth by $50 \%\left(\mathrm{EC}_{50}\right)$ values were calculated. The trial was repeated once.

Effect of fungicide application on disease development. A study was conducted to compare the efficacy of pyraclostrobin against sensitive and insensitive isolates inoculated onto field pea plants under controlled conditions, adapted from Thaher (2011). The study was set up in a randomized complete block design with four replicates and 10 pots per experimental unit. Six treatments were applied: (i) nontreated control (no fungicide, no inoculation); (ii) pyraclostrobin application only (fungicide control); (iii) inoculation with sensitive isolates only (inoculated control); (iv) inoculation with insensitive isolates only (inoculated control); (v) pyraclostrobin application, then inoculation with sensitive isolates; and (vi) pyraclostrobin application, then inoculation with insensitive isolates.

Ten plants of field pea 'CDC Meadow' were grown in each 15-cmdiameter pot of soil-less mix (ProMix BX; Premier Horticulture) in a growth chamber set with a 16 -h photoperiod at $20^{\circ} \mathrm{C}$ (day) and $15^{\circ} \mathrm{C}$ (night). The spore suspensions were produced using the procedure from the conidial germination study, with conidia of five randomly selected insensitive isolates combined into one spore suspension, and a similar spore suspension prepared using five sensitive isolates. The plants were sprayed to saturation with the recommended rate of pyraclostrobin $(0.04 \mathrm{ml}$ per $10 \mathrm{ml}$ of water) at 21 days after planting and inoculated 1 day later by spraying plants with a spore suspension $\left(2 \times 10^{5}\right.$ spores $\left.\mathrm{ml}^{-1}\right)$. A handheld spray bottle was used for both fungicide application and inoculation. After inoculation, the pots were incubated in a transparent-plastic moist chamber at high humidity for $48 \mathrm{~h}$ with a $16-\mathrm{h}$ photoperiod at $18^{\circ} \mathrm{C}$ (day) and $15^{\circ} \mathrm{C}$ (night). The plants were then returned to the growth chamber, where the humidity was kept as high as possible with the use of a humidifier. Each plant was rated for Mycosphaerella blight lesion severity at 7 days after inoculation using the 0-to-9 scale of Xu et al. (1996), where $0=$ no disease symptoms and $9=$ the plant is completely covered with lesions.

Data analysis. For each isolate in the radial growth studies, mean growth per treatment was converted to a percentage of the growth of an unamended control, as follows: [1 - (growth on amended medium/growth on unamended medium $) \times 100]$. In the conidial germination study, counts were converted to percent germination relative to the unamended control, as follows: [1 - (germination on amended medium/germination on unamended medium) $\times 100$ ] (Thaher 2011). In the study to assess the effect of SHAM, the two response curves for each isolate with and without SHAM were graphed and tested against each other to identify differences.

All statistical analyses were conducted using SAS 9.2 (SAS Institute Inc., Cary, NC) and differences were considered significant at $P \leq 0.05$. The $\mathrm{EC}_{50}$ value represents the effective concentration of the amount of fungicide active ingredient required to inhibit growth of the pathogen by $50 \%$. The $\mathrm{EC}_{50}$ values for each isolate for both radial growth and conidial germination were determined by fitting the data to a nonlinear equation and using nonlinear regression (PROC NLIN). The residual data were tested for normality using PROC UNIVARIATE (Shapiro-Wilk test; Wise et al. 2008), and did not follow a normal curve because of the nonlinear dose response of the pathogen. To normalize the residuals, the data were transformed using a square root transformation. To compute variance and eliminate outliers, mean $\mathrm{EC}_{50}$ values that were three, two, and then one standard deviations from the mean were removed from the data set (R. C. Yang, University of Alberta, personal communication).

Analysis of variance (ANOVA) was conducted for each isolate within a data set. The ANOVA tables used to obtain the $\mathrm{EC}_{50}$ values were then compared against each other. $F$ tests were conducted on the values obtained from the ANOVA tables to ensure homogeneity of the data (Wise et al. 2009). Once the data were homogeneous, the value was recorded and a discriminatory dose was chosen from the homogeneous data set (R. C. Yang, University of Alberta, personal communication).

Table 2. Effective concentration to inhibit $50 \%$ growth $\left(\mathrm{EC}_{50}\right)$ of baseline isolates of Mycosphaerella pinodes, based on radial growth of media amended with formulated product (FP) and technical-grade (TG) pyraclostrobin with and without salicylhydroxamic acid (SHAM)

\begin{tabular}{|c|c|c|c|}
\hline \multirow[b]{2}{*}{ Isolate } & \multicolumn{3}{|c|}{$\mathrm{EC}_{50}\left(\mu \mathrm{g} \mathrm{ml}^{-1}\right)^{\mathrm{a}}$} \\
\hline & No SHAM FP & With SHAM FP & With SHAM TG \\
\hline R010R & 0.104 & 0.074 & N/A \\
\hline Sep0002 & 0.072 & 0.187 & 0.116 \\
\hline Sep0004 & 0.076 & 0.165 & 0.136 \\
\hline Sep0008 & 0.077 & 0.114 & 0.059 \\
\hline Mar0405 & 0.216 & 0.152 & 0.059 \\
\hline Mar0412 & 0.075 & 0.090 & 0.118 \\
\hline Mar0413 & 0.131 & 0.137 & 0.142 \\
\hline Mar0419 & 0.121 & 0.091 & 0.169 \\
\hline Mar0425 & 0.199 & 0.107 & 0.092 \\
\hline Mar0426 & 0.110 & 0.101 & 0.099 \\
\hline Mar0427 & 0.121 & 0.090 & 0.084 \\
\hline Mar0435 & 0.071 & 0.065 & 0.050 \\
\hline Mar0448 & 0.122 & 0.173 & 0.137 \\
\hline Mar0452 & 0.128 & 0.179 & 0.147 \\
\hline Mar0458 & 0.185 & 0.167 & 0.125 \\
\hline Mar0460 & 0.151 & 0.166 & N/A \\
\hline Mar0463 & 0.052 & 0.149 & 0.100 \\
\hline Mar0464 & 0.139 & 0.084 & 0.102 \\
\hline Apr0404 & 0.078 & 0.169 & 0.063 \\
\hline Apr0405 & 0.133 & 0.149 & 0.142 \\
\hline Apr0409 & 0.100 & 0.089 & 0.095 \\
\hline Aug0002 & 0.065 & 0.079 & 0.034 \\
\hline Aug0004 & 0.031 & 0.092 & 0.037 \\
\hline Aug0006 & 0.091 & 0.082 & 0.036 \\
\hline Nov0456 & 0.295 & 0.128 & 0.124 \\
\hline MP01 & 0.209 & 0.203 & 0.117 \\
\hline MP03 & 0.091 & 0.094 & 0.066 \\
\hline MP04 & 0.121 & 0.216 & 0.146 \\
\hline MP05 & 0.093 & 0.089 & 0.077 \\
\hline MP06 & 0.117 & 0.120 & 0.124 \\
\hline MP07 & 0.185 & 0.148 & 0.150 \\
\hline MP08 & 0.177 & 0.206 & N/A \\
\hline MP09 & 0.150 & 0.142 & N/A \\
\hline MP10 & 0.100 & 0.180 & 0.118 \\
\hline MP11 & 0.138 & 0.153 & 0.110 \\
\hline MP12 & 0.158 & 0.129 & 0.142 \\
\hline MP14 & 0.148 & 0.156 & 0.188 \\
\hline MP15 & 0.090 & 0.104 & 0.093 \\
\hline MP17 & N/A & 0.164 & 0.241 \\
\hline MP18 & N/A & 0.189 & 0.123 \\
\hline MP22 & 0.081 & 0.128 & 0.176 \\
\hline MP23 & 0.145 & 0.130 & N/A \\
\hline MP24 & 0.248 & 0.185 & 0.240 \\
\hline MP26A & 0.057 & 0.108 & 0.159 \\
\hline MP26B & 0.106 & 0.121 & 0.126 \\
\hline MP27 & 0.087 & 0.104 & 0.150 \\
\hline MP28 & 0.145 & 0.104 & 0.119 \\
\hline MP30 & 0.173 & 0.137 & 0.148 \\
\hline AP10 & N/A & 0.067 & 0.125 \\
\hline
\end{tabular}

${ }^{a}$ N/A - not available. 
To assess the effect of the pyraclostrobin source on the expression of sensitivity in the baseline isolates, the two response curves (formulated versus technical-grade active ingredient) for each isolate were tested against each other independently to compare the $\mathrm{EC}_{50}$ values and graphed. The data were tested to ensure that the assumptions of ANOVA were met and means were separated using Fisher's protected least significant difference at $P \leq 0.05$. The data were then log-transformed to linearize the logarithmic curve and compared using the general linear model (PROC GLM). Although the isolates would be considered a random effect, because each isolate was tested individually, isolates were not included in the model statement. The same $\log$ transformation and statistical analysis was used to assess the effect of SHAM (with and without SHAM added; R. C. Yang, University of Alberta, personal communication).

The $\mathrm{EC}_{50}$ values for the insensitive isolates were determined using nonlinear regression (PROC NLIN). Treatment means between the insensitive and sensitive isolates from all geographical areas were compared using the general linear model (PROC GLM) with
Tukey's multiple range test and orthogonal single-degree-of-freedom contrasts.

\section{Results}

Baseline sensitivity. Radial growth assessments. In the initial radial growth study of the baseline isolates, there was no main effect of isolate or source of pyraclostrobin (technical-grade versus formulated product) (Table 1). Data indicated that the range of $\mathrm{EC}_{50}$ values was between 0.05 and $0.1 \mathrm{mg} \mathrm{liter}^{-1}$ a.i. (Fig. 1). The $\mathrm{EC}_{50}$ values of individual isolate for pyraclostrobin were 0.03 to $0.29 \mathrm{mg} \mathrm{liter}^{-1}$, with a mean of $0.12 \mathrm{mg} \mathrm{liter}^{-1}$ (Table 2). In companion trials, there was no significant effect of adding SHAM to the media (Table 3) and there were no differences in the $\mathrm{EC}_{50}$ values (Table 2). When graphed and compared, the response curves of the two data sets for each isolate were similar (Fig. 2; Supplementary Fig. S1). All isolates were sensitive to pyraclostrobin.

Conidial germination assessment. Similarly, conidial germination of the baseline isolates in response to pyraclostrobin varied slightly

Table 3. Analysis of variance for radial growth of the baseline isolates of Mycosphaerella pinodes isolates in response to the formulated product of pyraclostrobin with and without salicylhydroxamic acid

\begin{tabular}{|c|c|c|c|c|c|}
\hline Isolate & $\operatorname{Pr}>F$ & $F$ value & $R^{2}$ & Coefficient of variation & $\log _{10}$ growth $^{\mathrm{a}}$ \\
\hline \multicolumn{6}{|c|}{ Saskatchewan } \\
\hline R010R & 0.176 & 2.04 & 0.91 & 24.79 & 1.25 \\
\hline Sep0002 & 0.138 & 2.44 & 0.90 & 45.75 & 1.02 \\
\hline Sep0004 & 0.009 & 9.05 & 0.94 & 26.89 & 1.11 \\
\hline Sep0008 & 0.042 & 5.03 & 0.97 & 12.45 & 1.27 \\
\hline Mar0405 & 0.166 & 2.13 & 0.94 & 17.04 & 1.33 \\
\hline Mar0412 & 0.186 & 1.94 & 0.90 & 34.24 & 1.14 \\
\hline Mar0413 & 0.998 & 0.00 & 0.95 & 16.04 & 1.27 \\
\hline Mar0419 & 0.616 & 0.26 & 0.97 & 12.26 & 1.26 \\
\hline Mar0425 & 0.298 & 1.17 & 0.92 & 34.43 & 1.10 \\
\hline Mar0426 & 0.522 & 0.43 & 0.96 & 11.81 & 1.35 \\
\hline Mar0427 & 0.285 & 1.24 & 0.95 & 19.87 & 1.17 \\
\hline Mar0435 & 0.028 & 6.01 & 0.92 & 29.51 & 1.13 \\
\hline Mar0448 & 0.101 & 3.08 & 0.95 & 15.65 & 1.29 \\
\hline Mar0458 & 0.081 & 3.55 & 0.91 & 26.61 & 1.21 \\
\hline Mar0460 & 0.930 & 0.01 & 0.96 & 13.74 & 1.28 \\
\hline Mar0464 & 0.117 & 2.79 & 0.92 & 31.21 & 1.15 \\
\hline Apr0404 & 0.052 & 4.50 & 0.96 & 15.58 & 1.25 \\
\hline Apr0405 & 0.246 & 1.47 & 0.96 & 14.98 & 1.28 \\
\hline Apr0409 & 0.123 & 2.69 & 0.92 & 34.90 & 1.09 \\
\hline Aug0002 & 0.129 & 2.62 & 0.86 & 42.92 & 1.11 \\
\hline Aug0004 & 0.040 & 5.14 & 0.85 & 52.00 & 1.07 \\
\hline Aug0006 & 0.413 & 0.71 & 0.81 & 60.64 & 1.09 \\
\hline Nov0456 & 0.178 & 2.01 & 0.93 & 16.38 & 1.38 \\
\hline \multicolumn{6}{|l|}{ Washington } \\
\hline MP01 & 0.159 & 2.21 & 0.96 & 12.25 & 1.33 \\
\hline MP03 & 0.493 & 0.50 & 0.95 & 18.01 & 1.23 \\
\hline MP04 & 0.802 & 0.07 & 0.95 & 13.72 & 1.33 \\
\hline MP05 & 0.067 & 3.87 & 0.77 & 27.19 & 1.34 \\
\hline MP06 & 0.007 & 10.0 & 0.96 & 17.13 & 1.20 \\
\hline MP07 & 0.660 & 0.20 & 0.95 & 10.31 & 1.45 \\
\hline MP08 & 0.212 & 1.72 & 0.92 & 12.27 & 1.51 \\
\hline MP09 & 0.027 & 6.07 & 0.96 & 15.26 & 1.24 \\
\hline MP10 & 0.261 & 1.38 & 0.92 & 17.76 & 1.39 \\
\hline MP11 & 0.742 & 0.11 & 0.90 & 24.32 & 1.30 \\
\hline MP12 & 0.777 & 0.08 & 0.92 & 18.89 & 1.31 \\
\hline MP14 & 0.230 & 1.59 & 0.94 & 14.66 & 1.38 \\
\hline MP15 & 0.146 & 2.37 & 0.95 & 15.01 & 1.25 \\
\hline MP22 & 0.020 & 6.92 & 0.97 & 14.64 & 1.20 \\
\hline MP23 & 0.033 & 5.53 & 0.72 & 45.47 & 1.23 \\
\hline MP24 & 0.156 & 2.27 & 0.87 & 24.07 & 1.41 \\
\hline MP26A & 0.637 & 4.05 & 0.97 & 21.16 & 1.00 \\
\hline MP26B & 0.524 & 0.43 & 0.98 & 8.15 & 1.35 \\
\hline MP27 & 0.120 & 2.75 & 0.96 & 19.91 & 1.10 \\
\hline MP28 & 0.582 & 0.40 & 0.94 & 16.62 & 1.28 \\
\hline MP30 & 0.555 & 0.37 & 0.96 & 8.63 & 1.45 \\
\hline
\end{tabular}

${ }^{a}$ Dependent variable was $\log _{10}$ transformation of percent growth response with 1 degree of freedom and $P \leq 0.05$. 
but did not differ significantly among isolates or source of pyraclostrobin. Data indicated that the $\mathrm{EC}_{50}$ value was approximately $0.01 \mathrm{mg} \mathrm{liter}^{-1}$ a.i. (Supplementary Fig. S2). The $\mathrm{EC}_{50}$ values for pyraclostrobin were 0.008 to $0.041 \mathrm{mg} \mathrm{liter}^{-1}$, with a mean of $0.015 \mathrm{mg} \mathrm{liter}^{-1}$ (Supplementary Table S1). Although the $\mathrm{EC}_{50}$ values were lower than for the radial growth procedure, based on conidial germination, the classification of the isolates were the same and they were sensitive to pyraclostrobin.

Sensitivity of $M$. pinodes isolates collected in 2010 and 2011. Testing for sensitivity. The sensitivity to pyraclostrobin of 324 isolates from four geographical areas (Saskatchewan, Alberta, Washington, and North Dakota) was assessed at a discriminatory dose of $5.0 \mathrm{mg} \mathrm{liter}{ }^{-1}$ using the radial growth procedure. Of those isolates, 19 were insensitive, 304 were sensitive, and 1 was intermediate (Table 4; Supplementary Table S2; Supplementary Fig. S3) based on the classification system outlined above. The 19 isolates that were identified as insensitive were assessed using the conidial germination procedure at a discriminatory dose of $0.1 \mathrm{mg} \mathrm{liter}^{-1}$. The isolates followed the same response pattern and were classified as insensitive (Table 4). Of the 19 insensitive isolates, 9 were collected from central Alberta, 5 from north-central Alberta, and 5 from across central and southern Saskatchewan (Table 4).

$E C_{50}$ of insensitive isolates. The radial growth response of the insensitive isolates to the high concentrations of the pyraclostrobin fungicide varied. Data indicated $\mathrm{EC}_{50}$ values as high as $260 \mathrm{mg} \mathrm{liter}^{-1}$ and as low as $120 \mathrm{mg} \mathrm{liter}{ }^{-1}$. Upon analysis, the $\mathrm{EC}_{50}$ values for the 19 insensitive isolates indicated pyraclostrobin at 80 to $261 \mathrm{mg} \mathrm{liter}{ }^{-1}$, with a mean of $180 \mathrm{mg} \mathrm{liter}^{-1}$ (Table 4). The dose response curve and $\mathrm{EC}_{50}$ values for the insensitive isolates differed significantly from that of the sensitive isolates (Fig. 3). The mean $\mathrm{EC}_{50}$ value of the insensitive isolates was nearly 1,500 times higher than the mean for the sensitive isolates.

Effect of fungicide application on disease development. Application of pyraclostrobin had no effect on Mycosphaerella blight severity resulting from inoculation with the insensitive isolates but substantially reduced severity on the plants inoculated with the sensitive isolates. The mean Mycosphaerella blight rating for the sensitive isolates sprayed with the fungicide was 0.2 (of 9), whereas the mean rating of the insensitive isolates was 6.4.

\section{Discussion}

Repeated application of strobilurin fungicides during the growing season is the most effective option for management of $M$. pinodes on field pea (Bretag 1985; Warkentin et al. 2000). However, strobilurins

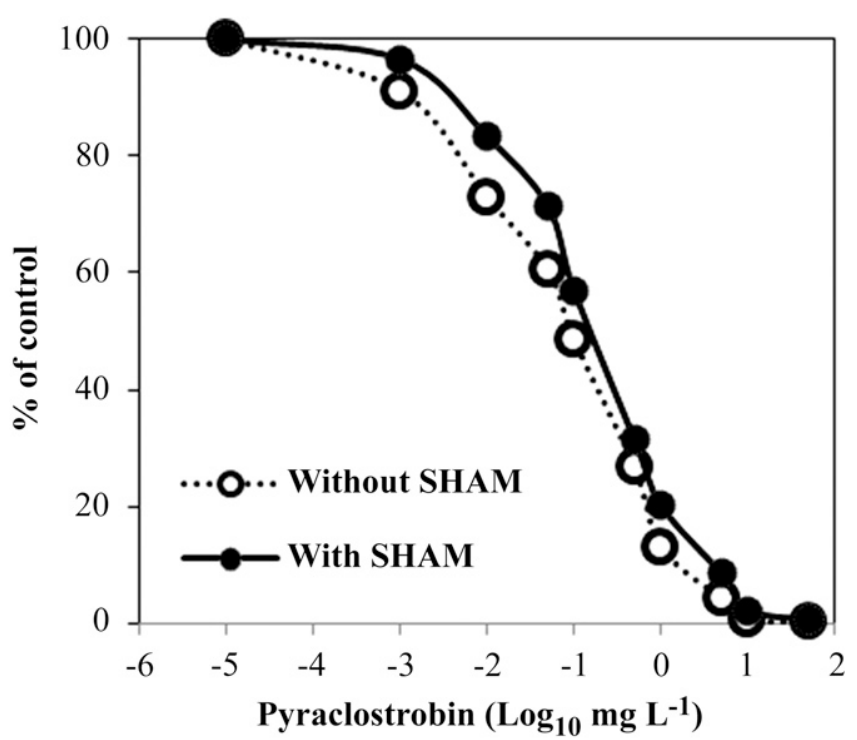

Fig. 2. Dose response curves for radial growth of a representative sensitive isolate of Mycosphaerella pinodes (Apr0404) to the formulated product of pyraclostrobin, with and without salicylhydroxamic acid (SHAM), relative to a nontreated control. have a very site-specific mode of action; therefore, many pathogen populations have a high risk of development of insensitivity within the pathogen population. Repeated application increases the selection pressure for fungicide insensitivity (Gisi et al. 1997; Ma and Michailides 2005). Insensitivity to the strobilurins has already been reported in populations of several pathogens in the genus Mycosphaerella and has also developed in populations of A. rabiei on chickpea across the Northern Great Plains (Gossen et al. 2008; Thaher 2011; Wise et al. 2008, 2009). Therefore, a study to develop a baseline for $M$. pinodes for sensitivity to strobilurin fungicides and to determine the occurrence in the shift in pyraclostrobin sensitivity was timely. This is the first report of isolates of $M$. pinodes that are insensitive to pyraclostrobin.

The baseline sensitivity of $M$. pinodes to pyraclostrobin was established based on the $\mathrm{EC}_{50}$ value response of 70 isolates collected from western Canada, the northern Great Plains, and the northwestern United States. Insensitivity to a fungicidal mode of action may occur in a pathogen population that has not been previously exposed to that fungicide as a consequence of naturally occurring mutations (Brent and Holloman 2007b) or even insensitivity of the entire species. In the current study, there was concern that such isolates could be represented in the sample and could affect the baseline measurement. However, each of the isolates in the baseline sensitivity assessment had a substantial level of inhibition by the fungicide and we concluded that each of the isolates in the baseline collection was sensitive to pyraclostrobin.

There are two main methodologies used to test the sensitivity of a pathogen to a fungicide in vitro: radial growth and conidial germination. Several studies have reported that conidial germination was more effective than radial growth for assessment of pathogen insensitivity (Demirci et al. 2003; Vincelli and Dixon 2002). In the current study, the $\mathrm{EC}_{50}$ values of the baseline isolates were much lower in the conidial germination assay $\left(0.008\right.$ to $\left.0.041 \mathrm{mg} \mathrm{liter}^{-1}\right)$ than in the radial growth assay ( 0.031 to $0.294 \mathrm{mg} \mathrm{liter}^{-1}$ ) but there were no differences in the classification of isolates using either method.

Previous research involving in vitro testing indicated that SHAM is necessary to inhibit alternative respiration in some pathogens to minimize the incidence of false negatives for insensitivity. For example, there were differences in the $\mathrm{EC}_{50}$ values with and without SHAM for A. rabiei (Wise et al. 2008, 2009). However, another study reported that differences associated with SHAM in A. rabiei were much smaller than those associated with the qualitative resistance; therefore, SHAM was not essential for differentiating sensitive

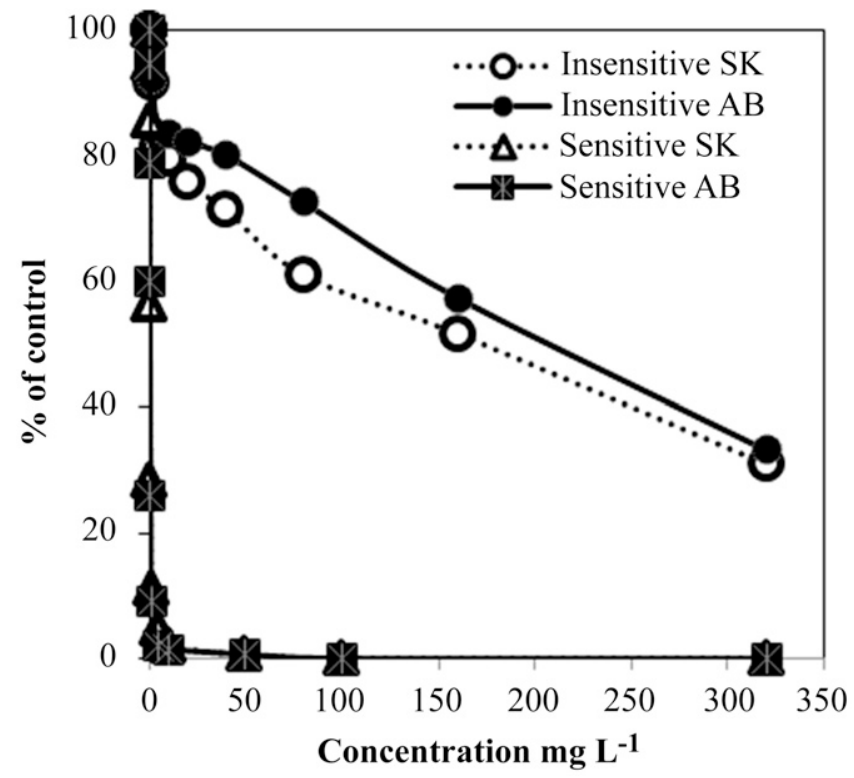

Fig. 3. Dose response curve of the mean of all Mycosphaerella pinodes isolates that were insensitive and sensitive to the formulated product of pyraclostrobin fungicide collected from Alberta (AB) and Saskatchewan (SK) in 2010 and 2011. 
and insensitive isolates for routine assessments (Thaher 2011). In the current study, there were no significant differences in the $\mathrm{EC}_{50}$ values or response curves with or without SHAM. However, even though alternative respiration was not detected, SHAM was included in the insensitivity testing of isolates collected in 2010 and 2011 as a precaution to ensure that an accurate response to the fungicide was obtained.

Both formulated product and technical-grade active ingredients of pyraclostrobin have been used in testing for fungicide insensitivity in previous in vitro studies. Formulated product is more readily available than technical-grade active ingredient but the components of the formulation may occasionally affect the results. In the current study, however, there was no difference between formulated product and the technical-grade active ingredient.

The discriminatory dose used to test for insensitivity needs to be appropriate to the pathogen, the combination with the fungicide, and the research being conducted. Concentrations range from 4 to $200 \times$ the baseline EC $_{50}$ (Avila-Adame et al. 2003; Mondal et al. 2005; Rebollar-Alviter et al. 2007; Wise et al. 2009). In all research conducted, the dose is chosen based on previous growth observations. A discriminatory dose of $5 \mathrm{mg} \mathrm{liter}^{-1}$ was selected to assess the isolates collected in 2010 and 2011, which was about 50x the baseline $\mathrm{EC}_{50}$ and $2.5 \times$ the recommended application rate. This level was chosen to identify only highly insensitive isolates. At this high concentration of pyraclostrobin, sensitive isolates were only capable of slow growth, whereas the growth of highly insensitive isolates was only slightly reduced.

Only 19 of the 324 isolates of $M$. pinodes collected from the four geographical areas in 2011 and 2012 were insensitive to pyraclostrobin and 1 isolate had intermediate sensitivity. Although sensitivity to only one strobilurin fungicide, pyraclostrobin, was examined, crossresistance among the actives in the strobilurin group is the norm due to their highly specific mode of action (Avila-Adame et al. 2003; Bartlett et al. 2002).

There are two mutations in the mitochondrial cytochrome $\mathrm{b}$ gene known to confer insensitivity to strobilurins: G143A and F129 L (Gisi et al. 2000; Torriani et al. 2009). The G143A mutation is a single nucleotide change on amino acid 143 from glycine to alanine and results in qualitative insensitivity. The F129 L mutation is a change on amino acid 129 from phenylalanine to leucine, which produces only moderate insensitivity; therefore, effective disease reduction with QoI fungicides is still possible (Gisi et al. 2000). The high level of insensitivity detected in the 19 pyraclostrobin-insensitive isolates of $M$. pinodes indicates that it is the result of the G143 mutation. Therefore, increasing the amount of fungicide used or the frequency of fungicide application will not result in disease suppression. Indeed, in the current study, the average $\mathrm{EC}_{50}$ value of the insensitive isolates was determined to be $180 \mathrm{mg} \mathrm{liter}^{-1}$, which corresponds to about $65 \times$ the label rate.

Of the 19 pyraclostrobin-insensitive isolates, 9 isolates were collected from Central Alberta, where field pea is grown intensively and fungicides are applied almost every year as a preventative measure. Five of the insensitive isolates were collected from more northern areas of Alberta, where field pea cultivation is also widespread and pyraclostrobin is frequently used. The remaining five isolates were collected from across central and southern Saskatchewan, where field pea is frequently encountered but not a normal component of the cropping rotation in every field. None of the isolates collected from North Dakota or Washington State were classified as insensitive. This may reflect less frequent exposure of the pathogen population to strobilurin fungicides in those areas. The acreage of field pea in Canada is about seven times higher than in the United States, and that disparity is increasing (USDA 2010). More intensive production of field pea has almost certainly resulted in a more frequent application of pyraclostrobin for Mycosphaerella blight management, with a corresponding increase in the intensity of selection pressure for insensitive strains. More frequent cultivation of a susceptible host, a large pathogen population, and frequent application of fungicide all favor the occurrence of insensitive individuals in the population. Nevertheless, the prevalence of insensitive strains may eventually increase even in areas where selection pressure is not high, because of the airborne nature of the sexual spores of $M$. pinodes. Fungicidal insensitivity can be spread over long distances through the dissemination of airborne ascospores (Torriani et al. 2009).

When insensitive isolates were inoculated onto pea plants and sprayed with pyraclostrobin to observe the response in planta, the insensitive isolates caused severe foliar symptoms, similar to that in the nonsprayed but inoculated control, but almost no disease developed following inoculation of fungicide-treated plants with sensitive isolates. These results indicate that the aggressiveness of the insensitive isolates is similar to that of sensitive isolates. Under field conditions, insensitive isolates generally become more common because of the selection pressure imposed by continued fungicide application (Ma

Table 4. Isolates of Mycosphaerella pinodes collected in 2010 and 2011 from Saskatchewan and Alberta with reduced sensitivity to pyraclostrobin fungicide (formulated product), based on reduction in radial growth and conidial germination

\begin{tabular}{|c|c|c|c|c|c|}
\hline Year & Culture & Growth reduction $(\%)$ & Germination reduction $(\%)$ & $\mathrm{EC}_{50}\left(\mu \mathrm{g} \mathrm{ml}^{-1}\right)$ & Classification \\
\hline \multicolumn{6}{|l|}{ Alberta } \\
\hline \multirow[t]{5}{*}{2010} & Barrhead 8 & 28.57 & 6.33 & 144.4 & Insensitive \\
\hline & Barrhead 7 & 25.33 & 9.76 & 260.7 & Insensitive \\
\hline & Barrhead 6 & 16.89 & 9.12 & 186.0 & Insensitive \\
\hline & Mannville F11A-2 & 16.86 & 1.68 & 211.5 & Insensitive \\
\hline & Mannville F11A-4 & 15.18 & 11.33 & 255.2 & Insensitive \\
\hline \multirow[t]{9}{*}{2011} & Kelsey 5 & 30.74 & 4.18 & 176.0 & Insensitive \\
\hline & Hwy 61111 & 25.31 & 2.71 & 226.8 & Insensitive \\
\hline & Red Deer F1-3 & 20.95 & 16.60 & 149.0 & Insensitive \\
\hline & Lacombe F2-1 & 15.54 & 5.19 & 148.3 & Insensitive \\
\hline & Red Deer F2-3 & 15.14 & 19.63 & 161.3 & Insensitive \\
\hline & New Norway 1 & 10.41 & 2.51 & 216.5 & Insensitive \\
\hline & Hwy 6111 & -5.29 & 1.00 & 185.8 & Insensitive \\
\hline & Hwy 6115 & -10.61 & 7.88 & 230.5 & Insensitive \\
\hline & Hwy 6118 & -35.29 & 6.86 & 136.4 & Insensitive \\
\hline \multicolumn{6}{|c|}{ Saskatchewan } \\
\hline \multirow[t]{5}{*}{2010} & Swift Current 3 & 29.30 & 13.98 & 80.3 & Insensitive \\
\hline & Wingard Ferry 4 & 21.06 & 6.62 & 179.9 & Insensitive \\
\hline & Swift Current 6 & 16.22 & 17.72 & 189.2 & Insensitive \\
\hline & Wolsley 3 & 12.57 & 3.05 & 97.6 & Insensitive \\
\hline & Saskatoon 1 & -23.95 & -0.40 & 176.8 & Insensitive \\
\hline 2011 & Purdue 17 & 50.19 & N/A & 5.0 & Intermediate \\
\hline
\end{tabular}


and Michailides 2005). Thus, as long as the isolates remain pathogenic, and given the sexual reproduction of $M$. pinodes, the frequency of fungicide-insensitive isolates will likely continue to increase, and application of the fungicide will no longer be sufficient to control the disease. This will mean that strobilurins will not be effective in controlling $M$. pinodes in field pea and other fungicides will have to be used.

In chickpea, the increase in insensitive isolates and associated breakdown of effective Ascochyta blight reduction using strobilurin fungicides occurred over a period of only 2 to 3 years (Gossen et al. 2008; Thaher 2011; Wise et al. 2008, 2009), forcing producers to utilize a fungicide with an alternative mode of action. This type of abrupt change in the sensitivity to strobilurin fungicides has not yet been observed with $M$. pinodes, likely because of lower selection pressure. Only $6 \%$ of the 324 isolates of $M$. pinodes from across the northern Great Plains region were insensitive to the pyraclostrobin, while the overwhelming majority were sensitive. Pyraclostrobin has not been applied as intensively onto field pea as it has been on chickpea because many producers do not consider it economically feasible to make repeated applications of fungicide to field pea crops. However, the identification of insensitive isolates is a cause for concern. It is critically important to continue to monitor M. pinodes populations for increased frequency of strobilurin insensitivity. The agricultural industry must ensure the prudent use of this fungicide chemistry in the future and continue to work diligently to develop other management strategies, such as cultivar resistance for the control of Mycosphaerella blight in field pea.

\section{Acknowledgments}

We thank T. Dubitz, L. Schnepf, and L. Patterson for technical support; and BASF for funding support and providing the technical-grade product used in these studies.

\section{Literature Cited}

Ali, S. M., Paterson, J., and Crosby, J. 1982. A standard technique for detecting seed-borne pathogens in peas, chemical control and testing commercial seed in South Australia. Aust. J. Agric. Res. 22:348-352.

Avenot, H. F., and Michailides, T. J. 2007. Resistance to boscalid fungicide in Alternaria alternata isolates from pistachios in California. Plant Dis. 91: 1345-1350.

Avila-Adame, C., Olaya, G., and Koller, W. 2003. Characterization of Colletotrichum graminicola isolates resistant to strobilurin-related QoI fungicides. Plant Dis. 87:1426-1432.

Banniza, S., and Vandenberg, A. 2003. The influence of plant injury on development of Mycosphaerella pinodes in field pea. Can. J. Plant Pathol. 25:304-311.

Bartlett, D. W., Clough, J. M., Godwin, J. R., Hall, A. A., Hamer, M., and ParrDobranzki, B. 2002. The strobilurin fungicides. Pest Manage. Sci. 58:649-662.

BASF. 2011. Headline. Online publication. https://agro.basf.ca/West/Products/ HEADLINE.html

Beasse, C., Ney, B., and Tivoli, B. 1999. Effects of pod infection by Mycosphaerella pinodes in yield components of pea (Pisum sativum). Ann. Appl. Biol. 135:359-367.

Beasse, C., Ney, B., and Tivoli, B. 2000. A simple model of pea (Pisum sativum) growth affected by Mycosphaerella pinodes. Plant Pathol. 49:187-200.

Brent, K. J., and Holloman, D. W. 2007a. Fungicide resistance: The assessment of risk. Fungicide Resistance Action Committee, Monograph 2 (revised), Global Crop Protection Federation, Brussels. Online publication: http://www.frac. info/docs/default-source/publications/monographs/monograph-2.pdf

Brent, K. J., and Holloman, D. W. 2007b. Fungicide resistance in crop pathogens: How can it be managed (revised)? [Online]. Fungicide Resistance Action Committee, Monograph 1, Global Crop Protection Federation. Brussels. Online publication: http:// www.frac.info/docs/default-source/publications/monographs/monograph-1.pdf

Bretag, T. W. 1985. Chemical control of ascochyta blight of field peas. Australas. Plant Pathol. 14:42-43.

Bretag, T. W., Keane, P. J., and Price, T. V. 2006. The epidemiology of ascochyta blight in field peas: A review. Aust. J. Agric. Res. 57:883-902.

Chang, K. F., Ahmed, H. U., Hwang, S. F., Gossen, B. D., Strelkov, S. E., Blade, S. F., and Turnbull, G. D. 2007. Sensitivity of field populations of Ascochyta rabiei to chlorothalonil, mancozeb, and pyraclostrobin fungicides, and effects of strobilurin fungicides on the progress of ascochyta blight of chickpea. Can. J. Plant Sci. 87:937-944.
Chilvers, M. I., Rogers, J. D., Dugan, F. M., Stewart, J. E., Chen, W., and Peever, T. 2009. Didymella pisi sp. nov., the teleomorph of Ascochyta pisi. Mycol. Res. 113:391-400.

Conner, R. L., Hwang, S. F., Woods, S. M., Chang, K. F., Bing, D. J., Dongfang, Y., Su, H., McAndrew, D. W., and Yager, L. M. 2007. Influence of agronomic traits on the expression of tissue-specific resistance to mycosphaerella blight in field pea. Can. J. Plant Sci. 87:157-165.

Davidson, J. A., and Ramsey, M. D. 2000. Pea yield decline syndrome in South Australia: The role of diseases and the impact of agronomic practices. Aust. J. Agric. Res. 51:347-354.

Demirci, F., Bayraktar, H., Babaliogullu, I., Dolar, F. S., and Maden, S. 2003. In vitro and in vivo effects of some fungicides against the chickpea blight pathogen, Ascochyta rabiei. J. Phytopathol. 151:519-524.

FRAC. 2015. FRAC Code List 2015: Fungicides sorted by mode of action. Fungicide Resistance Action Committee. Online publication.

Gisi, U., Chin, K. M., Knapova, G., Farber, R., Kung, R., Mohr, U., Parisi, S. Sierotzki, H., and Steinfeld, U. 2000. Recent developments in elucidating modes of resistance to phenylamide, DMI and strobilurin fungicides. Crop Prot. 19:863-872.

Gisi, U., Hermann, D., Ohl, L., and Steden, C. 1997. Sensitivity profiles of Mycosphaerella graminicola and Phytophthora infestans populations to different classes of fungicides. Pestic. Sci. 51:290-298.

Gossen, B. D., and Anderson, K. L. 2004. First report of resistance to strobilurin fungicides in Didymella rabiei. Can. J. Plant Pathol. 26:411.

Gossen, B. D., Carisse, O., Kawchuk, L., Van Der Heyden, H., and McDonald, M. R. 2014. Recent changes in fungicide use and fungicide insensitivity in crop pathogens in Canada. Can. J. Plant Pathol. 36:327-340.

Gossen, B. D., Chang, K. F., Hwang, S. F., and McDonald, M. R. 2008. Change in sensitivity of Ascochyta rabiei to strobilurin fungicides in Saskatchewan, 20022006. Can. J. Plant Pathol. 30:384-385.

Grasso, V., Palermo, S., Sierotzki, H., Garibaldi, A., and Gisi, U. 2006 Cytochrome $b$ gene structure and consequences for resistance to Qo inhibitor fungicides in plant pathogens. Pest Manage. Sci. 62:465-472.

Keinath, A. 2009. Sensitivity to azoxystrobin in Didymella bryoniae isolates collected before and after field use of strobilurin fungicides. Pest Manage. Sci. 65:1090-1096.

Ma, Z., and Michailides, T. J. 2005. Advances in understanding molecular mechanisms of fungicide resistance and molecular detection of resistant genotypes in phytopathogenic fungi. Crop Prot. 24:853-863.

Miguez, M., Reeve, C., Wood, P. M., and Holloman, D. W. 2003. Rapid report. Alternative oxidase reduces the sensitivity of Mycosphaerella graminicola to QoI fungicides. Pest Manage. Sci. 60:3-7.

Mondal, S. N., Bhatia, A., Shilts, T., and Timmer, L. W. 2005. Baseline sensitivities of fungal pathogens of fruit and foliage of citrus to azoxystrobin, pyraclostrobin and fenbuconazole. Plant Dis. 89:1186-1194.

Olaya, G., and Koller, W. 1999. Diversity of kresoxim-methyl sensitivities in baseline populations of Venturia inaequalis. Pestic. Sci. 55:1083-1088.

Pasche, J. S., Wharman, C. M., and Gudmestad, N. C. 2004. Shift in insensitivity of Alternaria solani in response to QoI fungicides. Plant Dis. 88:181-187.

Rebollar-Alviter, A., Madden, L. V., Jeffers, S. N., and Ellis, M. A. 2007. Baseline and differential sensitivity to two QoI fungicides among isolates of Phytophthora cactorum that cause leather rot and crown rot on strawberry. Plant Dis. 91:1625-1637

Thaher, N. 2011. Fungicide Insensitivity in Ascochyta rabiei in Saskatchewan. M.Sc. thesis, University of Guelph, Guelph, ON, Canada.

Torriani, S. F. F., Brunner, P. C., McDonald, B. A., and Sierotzki, H. 2009. Qol resistance emerged independently at least 4 times in European populations of Mycosphaerella graminicola. Pest Manage. Sci. 65:155-162.

United States Department of Agriculture. 2010. Dry peas and lentils. Online publication. http://usda.mannlib.cornell.edu/MannUsda/viewDocumentInfo. do?documentID $=1578$

Vincelli, P., and Dixon, E. 2002. Resistance to QoI (strobilurin-like) fungicides in isolates of Pyricularia grisea from perennial ryegrass. Plant Dis. 86:235-240.

Warkentin, T. D., Xue, A. G., and McAndrew, D. W. 2000. Effect of mancozeb on the control of mycosphaerella blight of field pea. Can. J. Plant Sci. 80:403-406.

Wise, K. A., Bradley, C. A., Pasche, J. S., and Gudmestad, N. C. 2009. Resistance to QoI fungicides in Ascochyta rabiei from chickpea in the northern great plains. Plant Dis. 93:528-536.

Wise, K. A., Bradley, C. A., Pasche, J. S., Gudmestad, N. C., Dugan, F. M., and Chen, W. 2008. Baseline sensitivity of Ascochyta rabiei to azoxystrobin, pyraclostrobin and boscalid. Plant Dis. 92:295-300.

Xu, A. G., Warkentin, T. D., Greeiaus, M. T., and Zimmer, R. C. 1996. Genotypic variability in seedborne infection of field pea by Mycosphaerella pinodes and its relation to foliar disease severity. Can. J. Plant Pathol. 18:370-374.

Ypema, H. L., and Gold, R. E. 1999. Kresoxim-methyl. Plant Dis. 83:4-19.

Ziogas, B. N., Baldwin, B. C., and Young, J. E. 1997. Alternative respiration: A biochemical mechanism of resistance to azoxystrobin (ICIA 5504) in Septoria tritici. Pestic. Sci. 50:28-34. 